\title{
The Connection of Employer Branding to Recruitment: A Critique
}

\author{
Sonduru Weerawardane ${ }^{1}$ and Tharindu Weerasinghe ${ }^{2 *}$ \\ 1,2 Department of Human Resource Management, Faculty of Commerce and \\ Management Studies, University of Kelaniya, Sri Lanka \\ ${ }^{1}$ sonduruw@yahoo.com, ${ }^{2}$ tdtmdananjaya@gmail.com \\ * https://orcid.org/0000-0001-5096-6696
}

\begin{abstract}
The present paper reviews and summarizes the key findings of research on the connection of employer branding to employee recruitment with the prime focus of bridging the lacuna in extant literature, due to the inconsistency of aforesaid association across different contexts. Hence, building on social identity theory and job signaling theory, a content analysis of relevant research articles up to date was conducted. It is found that, more the organization/employer looks prestigious the more potentials will get attracted to the organization as being a member of it will improve the self-image too. Also found that, more the organizational attributes do match the personality / personalities of job seeks and communicate it properly, more the potentials will get attracted. The findings of the current review support the general notion that the congruence between individual identity and organizational identity plays a critical role in employer branding which in turn positive outcomes in the domain of recruitment
\end{abstract}

Keywords: Recruitment, Employer Brand, Employer Branding, Social Identity Theory, Person-Organization Fit

\section{Introduction}

Attracting the best and the brightest is vital for a company's survival and development since the human capital is a valuable resource that does contribute for the organization success (Xie, Bagozzi \& Meland, 2015). As the talent shortage has been increased within the global context, to attract and retain the best talent in organizations the 'employer brand' has been significantly used during last three decades (Theurer, Tumasjan, Welpe \& Lievens, 2016).

Ito, Brotheringe \& McFarland (2013) claimed that a favorable image; for an example being granted the award of the 'best employer award' will benefit the organization to attract the pool of talents. With the grown importance of this concept, businesses around the world have begun to improve in on building their employer brand or the Employee Value Proposition (EVP). Further, the Economist Magazine reported that effective EVP management can bring tangible benefits, including a 20 percent increase in the pool of potential workers, a four-fold increase in commitment among employees and a 10 percent decrease in payroll costs.

In the context of Sri Lanka, the employer branding has been an outburst concept. The Mervyn Raphael of People Business commented on the scope for Employer Branding in Sri Lanka as:

"Employer branding is a novel concept evolving in Sri Lanka. We see two prominent trends. First, there is a 
paradigm shift from the situation when branding was meant only for external communication-now the focus is to enhance employee experience, reduce image reality gaps and project differently as an employer to both internal and external stakeholders. Secondly, organizations across the globe maintain consistency in their employer brand experience and it is reflected in Sri Lanka too".

This reflects that in Sri Lanka the same importance is given to Employer Branding like in the global context. Further, it is reported in Central Bank of Sri Lanka (2017) that the top ten corporates of Sri Lanka have started building up their employer brand in order to attract the best talents. Now, the majority of companies have become the victims of the Brain drain that is prevalent within the country since many high skilled personnel tend to immigrate.

Further, it had been observed that the talented individuals tend to give up their current work place and incline to join another organization even at a lower designation as their main concern is becoming a member of a particular organization (Theurer, Tumasjan, Welpe \& Lievens, 2016).

The previous research studies which attempted to establish the association between employer brand and recruitment in different countries were found, but none of the studies were found which have been conducted in Sri Lanka. Hence, this review will help to bridge the gap in the context with more empirical validations in future.

This review paper provides definitions, descriptions and previous research findings pertaining to employer branding and recruitment. Additionally, the current paper reports the relevant theoretical overview to give a clear idea about the variables under review. Furthermore, a detailed understanding of the association between aforementioned two constructs; employer branding and recruitment will also be given in coming sub-sections of this article.

\section{Recruitment}

Employee recruitment is a process of finding and/or attracting applicants for the employer's open positions (Dessler, 2014). It includes the practices and activities carried out by the organization with the primary purpose of identifying and attracting potential employees (Breaugh \& Starke, 2000). Further, recruitment could be defined as organizational activities that affect the number and the type of applicants who apply for open positions (Sivertzen, Nilesen \& Olafsen, 2011). Simply, recruitment is all about attracting of a pool of candidates for a position that is vacant within an organization from which will select the most appropriate applicant to fill the vacancy.

The effective recruitment is important for an organization as it provides numerous benefits in the long run. To do effective recruitment Desseler (2014) emphasized that employers require a proper brand to differentiate themselves from other competitors and to gain competitive advantages in the labor market.

The recruitment could be done through internal sources that is current employees by hiring from within. The internal recruitment can lead to positive and negative results. It can motivate the current employees, the commitment and 
morale can be risen, the orientation costs will be lower. In the same way, rejections breed discontent; telling them why you rejected them and what remedial actions they might take is crucial, and employers require managers to post job openings and interview all inside candidates. Yet the manager often knows whom he or she wants to hire. Requiring him or her to interview a stream of unsuspecting "inside candidates" can be a waste of time for everyone (Desseler, 2014).

The Recruitment can be done through external sources too. They are recruitment via the online sources (such as; job portals, Linkedn, Facebook, Twitter), advertising the job positions in the newspapers, use of employee agencies, executive recruiters (also known as head-hunters) which is a special type employment agency employers retain to seek out topmanagement talent for their clients etc. Additionally, on-demand recruiting services which provide short-term specialized recruiting assistance to support specific projects without the expense of retaining traditional search firms, college recruitment, referrals could be done to attract the external candidates (Desseler, 2014).

HR managers need to monitor the effectiveness of recruitment methods. First, to ensure the value for money and, second, to ensure that the pool of applicants produced by various methods (either internal or external) is suitable. Breaugh \& Starke, (2000) outline many possible recruitment criteria against which recruitment activity can be measured. They included: (i) the number of applicants recruited; (ii) quality and diversity of applicants; (iii) cost per vacancy; (iv) speed of recruitment; (v) number of vacancies filled, (vi) ratio of offers to acceptances (Torrington et al., 2014).

\section{Attraction vs. Recruitment}

Employee recruitment and employer attractiveness have been defined as two distinct variables in extant literature.

Attractiveness is the benefits that a potential employee sees in an employment of a specific organization (Berthon et al., 2005; Siverston, Nilsen \& Olafsen, 2011). Also, it is identified that the employer attractiveness is the aim of the 'external brand image' of an organization (Arachchige \& Robertson, 2013). So, attractiveness is the expected outcome of the process of employer branding.

Siverston, Nilsen \& Olafsen, (2011) claim that the employer attractiveness has been measured using the 'empat scale'. The scale was developed by Berthon et al. (2005) which was derived from Ambler \& Barrow (1996) dimensions for psychological, functional and economic benefits. This scale consists of 25 items constituting five dimensions namely:

i) Interest value (innovation and interest in the product / services)

ii) Social Value (the work environment and relations to other employees)

iii) Economic Value (the economic benefits that employee could obtain)

iv) Development Value (the possibility for the future job opportunities) 
v) Application Value (the possibility to use what has been learned earlier in the workplace which is known as transfer of training)

Yet, these concepts; attraction and recruitment are defined as two unlike concepts. Thus, having considered the evidence in literature it could be reported that the employer attractiveness is embedded in the recruitment as it is identifying and attracting the potential candidates to the organization. As both the concepts are associated with the attractivity to the external parties and get them attracted to the organization, it can be stated that both concepts are similar in the real-world situations even though different in theory.

\section{The Concept of Brand in Corporate World}

"Your brand is what people say about you when you have left the room"; the statement stated by Larry Ellison, the founder of the Oracle does express the importance of having a powerful brand name for an organization (Robertson, 2013).

The American Marketing Association defines brand as "a name, term, sign, symbol, or design, or combination of them which is intended to identify the goods and services of one seller or group of sellers and to differentiate them from competitors".

A powerful brand should be memorable, meaningful, protectable and adaptive to changing situations. The more the brand name is powerful it will provide a higher competitive edge within the industry; especially in market capturing.
Within organizations there can be various brands existing in various aspects such as; consumer brand, company brand, employer brand etc. Wilden, Gudergan \& Lings (2010) mentioned that managing these brands for various stakeholders is a challenging task for any organization.

Nevertheless, these brands do have interconnections among each other. For an example, the companies which have low consumer awareness may find it hard to attract highly skilled human capital as potential recruits are less aware of the employer. Similarly, if the product brands are seen attractive in consumer markets, the potential recruits may have positive associations with the company and willing to join the company (Wilden, Gudergan \& Lings, 2010). Hence, having considered the above evidence, the current researchers could interpret the brand as an exclusive measurement that does differentiate themselves from another in order to obtain the competitive lead in the market or industry.

\section{Employer Brand}

Employer branding is a topic that does popular within the corporate world among the employers and as well as employees as a tool to attract and retain the human capital within the firms. Hence, the employer branding can be considered as the intersection of the Human Resource Management and Marketing Management. Similarly, it is the prime approach for recruitment challenges. Even though the concept has evolved from decades, the importance for this area has enhanced currently in the knowledge based economy where there's a shortage of skilled workers (Backhaus \& Tikoo, 2004). 
As per the definitions of Ambler and Barrow (1996), the founder of employer branding, defines the employer brand in terms of the benefits calling it as "the package of functional, economic and psychological benefits provided by the employment and identified with the employing company". Further, it was emphasized by the Ambler and Barrow (1996) that employees can maintain closer relationships with employers through employer brand, just like consumers do with product brands. Similarly, employer brand establishes the identity of the firm. It encompasses the firm's value system, policies and behaviors toward the objectives of attracting, motivating and retaining the firm's current and potential employees.

Employer brand targeted, the long term strategy to manage the awareness and perception of employees, potential employees, and related stakeholders with regards to a particular firm (Backhaus \& Tikoo, 2004). Similarly, Arachchige \& Robertson, (2013) mentioned that employer brand as the wholesome picture created within the employees and respective future employees' mind of the package of psychological, economic and functional benefits provided by employment and identified within a particular employer.

As identified by Backhaus \& Tikoo (2004) the employer brand does differ from the product brand based on the two key attributes. One, the employer brand is employment specific characterizing the identity of the employers, and two is employer brand does represent both to the internal and external parties whilst the product brand does concern the external audience.
Hence, the employer brand is considered as a portrait of psychological, economic and functional benefits of an organization that is reserved in the thoughts of the existing employees and potential applicants.

\section{Attributes and Perspectives of the Employer Brand}

The employer brand does associate with the symbolic and instrumental attributes. The symbolic attributes involved with the perceived company reputation and perceived organizational identity. The employer brand convey a meaning beyond the tangible benefits. The symbolic associations, the ideas presented by the brand play a significant role in providing the meaning in a person's social world.

The instrumental attributes are described as the job or organization in terms of objective, concrete and factual attributes that the job or organization either has or does not have (Xie, Bagozzi \& Meland, 2015). The examples for the instrumental attributes depicted are pay, bonuses, benefits, and possibility for career development. In developing the employer brand, it is required to pay attention to both the instrumental and symbolic attributes and include them appropriately by maintaining a trade-off between the both.

According to Theurer, Tumasjan, Welpe \& Lievens (2016) the employer branding is viewed based on three perspectives. First, in the job market perspective: that is employer branding is suggested to be used in the highly competitive job markets. Second, from a functional organizational perspective: that is the employer branding has been suggested to serve as a framework for career 
management programs as a novel concept in talent management. Third, from an HR cycle perspective: that is the employer branding target group has been generally considered to be both the potential employees for the recruitment and current employees for retention. In simple terms it conveys that the employer brand does help in the recruitment, retention, career management and act as a competitive edge in the job market where it could be concluded that employer branding is an essential tool for a proper functioning of the HRM activities within an organization now a days.

\section{Process of Building an Employer Brand}

Backhaus and Tikoo (2004) describe the employer branding as a three step process.

i) Developing a value preposition that is embodied in the brand. That includes the information about the organization culture, management style, qualities of current employees, current employee image and impressions of product.

ii) The Value Preposition should be marketed to its targeted potential employees; recruitment agencies etc. external marketing of the employer brand is done primarily to attract the target population.

iii) The third aspect of the employer branding is internal marketing. This is important as it carries the promises made to the recruits and incorporates as a part of the culture of the organization.

\section{Employer Branding Activities and Strategies}

Theurer, Tumasjan, Welpe \& Lievens, (2016) elaborated the employer branding activities and strategies as follows.

\section{Early Recruitment Activities}

Job seekers employer knowledge can be influenced by multiple different information sources. Firms must however strategically seek to communicate the specific image to bring the employees image in line with the projected images by the organization. This is basically done by the sponsorships and mainly through the word of mouth which is the strongest media and that can be basically done through the internal employees.

\section{High and Low Involvement Practice}

The low involvement practices require little consumer search and less involvement. As defined in the literature the low involvement practices are general recruitment ads, sponsorships. In opposition the high involvement practices requires more consumer search efforts. The High involvement practices are detailed recruitment plans, employee endorsements were best suited for companies that are generally well known and have positive image. For an example when a company does have an unfavorable reputation high information messages are powerful in changing the adverse applicant perceptions. 


\section{The Media Richness and Credibility}

The media richness and the source credibility is important in developing the Employer Brand. The channels that consist with low media richness such as; print and the channels that does have high media richness such as; internet should be used appropriately. The use of high media rich channels will allow the timely feedback and greater variety in the language. Further, it has been found out that the use of recruitment websites provides high media richness and have a strong impact on applicant attraction. As today, the potential candidates of generation $Y$ are looking for the information on Google, Job boards and social networks it is important to manage these channels well, by updating them continuously in order to manage the attributes of the employer brand in a strategic and proactive manner.

\section{Employer Branding Value Chain Model}

Theurer, Tumansjan, Welpe \& Lievens (2016) introduced an 'employer branding value chain model', which depicts the employer branding as a value chain. It does consist with overall framework on employer knowledge development and investment, applicant, employee mindset, firm performance and how the brand gives competitive advantage whilst enhancing the shareholder value. Figure 01 depicts the employer brand value chain model.

As the first stage of the model, the employer should concern on building the employer brand based on the three-step process that has been explained above by Backhaus \& Tikoo (2013). The employer brand should be positioned correctly among the potential and the current employees. Further throughout the model the consistency and clarity of the brand is emphasized. The brand should be consistent in every channel that is communicated and the message that is being conveyed by the brand should be transferred properly without any misalignment. Further, as stated above through the branding strategy the media that is used to convey the message should be strategically selected as it should be rich and credible.

In the second stage of the model it does concern on the mindset of the potentials and the employees regarding on the employer brand. The potentials will consider about the image or the reputation of the company, the person organization fit and job attributes pertaining to the organization which are being communicated through the employer brand and it will be discussed in detail in the latter part of the chapter. The current employees will subject to the change in the attitudes and actions through the activities communicated by the brand.

The third stage the model, emphasizes the organizational level outcomes that is gained through the employer brand for the competitive advantage and performance. These outcomes can be quantified through the job acceptance ratios, retention, or the turnover ratios etc. Further, in situations where the employer brand is powerful to the public such as in the public context, the employer brand will have spillover effects to the corporate and product brand that might affect the consumer purchasing patterns. 


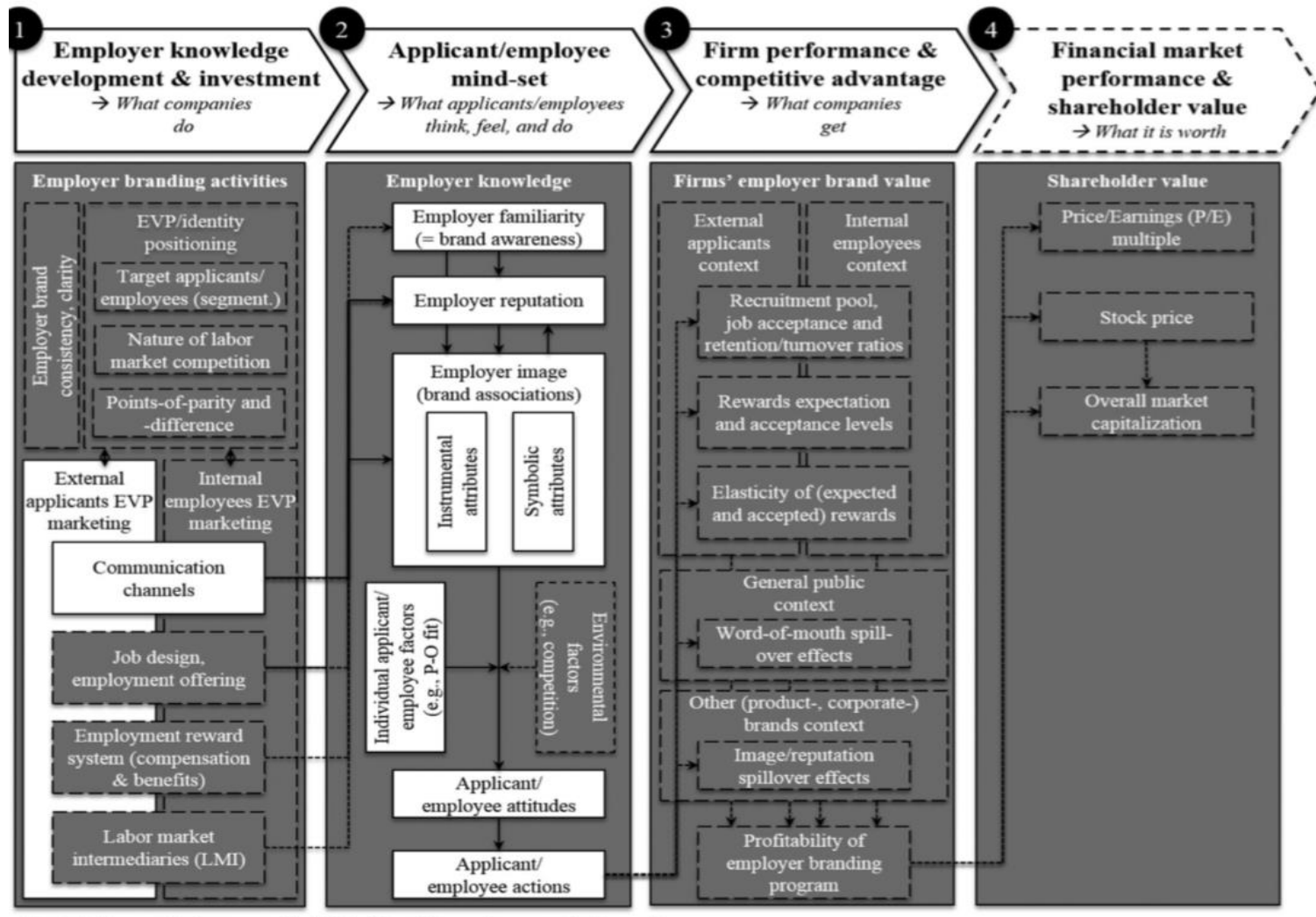

Note. Well-researched areas are highlighted in white, under-researched areas in grey

Figure 01: Employer Branding Value Chain Model Source: Backhaus and Tikoo (2013) 
In conclusion, in the fourth stage of the model employer brand value will be inter connecting with the financial outcomes of the organization such as to the shareholder value. They can be stated as the part of P/E ratio, Stock Price, Overall Market Capitalization etc.

Hence, when assessing the above model, the researcher can state that the building of an employer brand within an organization is like laying a foundation stone for an organization that will give numerous benefits in the long run.

\section{Employer Brand Equity}

The employer brand equity is the outcome of the employer branding activities. The employer brand equity propels the potential applicants to apply and the existing employees to retain. If the employer brand activities are successful it will result in the retention and the attraction of the potential and current employees too.

Alshathry, Clarke \& Goodman (2016) introduced a model namely employer brand equity typology that does derives the stages of the employer brand based on the two dimensions namely internal perceived employer brand equity and external employer brand equity.

Based on the framework the employer brand comes to a 'desirable status' when the employer brand perceived by both the potential and current employees is high. It is expected to retain and attract employees possibly and gives the organization a strong position in the labor market.

The second stage based on this framework is 'overstated employer brand'. That is where the employer brand is perceived highly by the potentials but it is low within the existing employees. In such situations it is likely to attract a high-level pool of applicants but tend to retain them lowly. To overcome that the employer should concern on the activities such as job redesign and the activities that will motivate the employees.

The 'emerging employer brand' is a situation where the internal perceived employer brand is high whilst the external potential perceived brand is low. This do not give an adverse impact to the organization in long run as the distinctive employment practices will be communicated to the external parties.

The situation where the perceived employer brand is weak in both the internal and external individuals that is known as 'undesirable employer brand'. In this situation the employer should begin with the employer brand composition phase that is emphasized by the Backhaus and Tikoo (2004) via a three step process. 


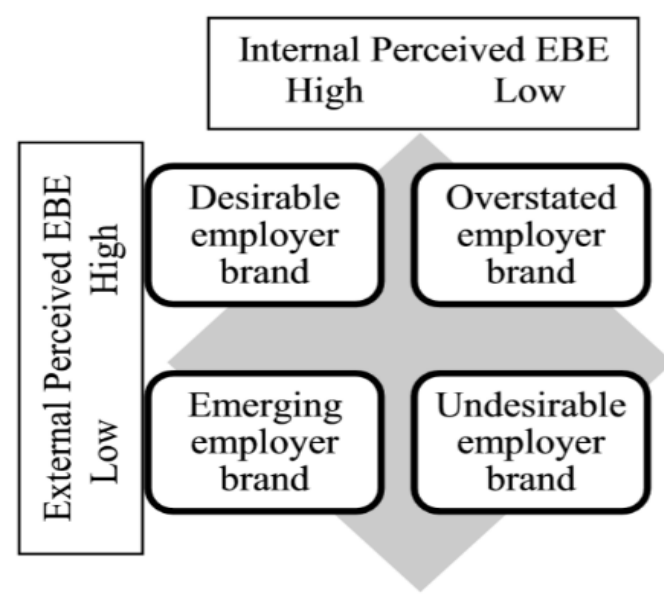

Figure 02: Perceived Employer Brand Equity

Source: The Role of Employer Brand equity in Employer Attraction and Retention: A Unified Framework (2016)

In simple terms it is required for an organization to understand the level that they are in and align their strategies based on the level of employer brand equity that they do possess. Further, the current researcher has identified that merely by constructing an employer brand is not sufficient. But it also should be continuously monitored and strategically manage in order to obtain the competitive advantage.

\section{Significance of Employer Branding}

As cited by Sokro (2012) the employer brand does provide economic and social benefits to the employees. It helps to attract the potentials and shapes their expectations about their employment. Also, it does align the existing employees to the organizational culture and strategy.
Arachchige and Robertson, (2013) mentioned that the employer branding is considered as a current management priority in leading companies due to the following reasons.

i) Shortage of the skilled labor.

ii) More with less; that is to mitigate the pressure by cutting the additional costs and increase the productivity by recruiting the right people for the right jobs.

iii) Growth and Profitability.

iv) Popularity; that is to increase the popularity of the employers through maintaining the opportunities.

v) Strength; when the employer brand is attractive it will enhance the power of organizations to retain and attract potential employees to the organization. 
The goal of the employer branding is to become the employer brand of choice. To become an employer brand of choice the company should become a distinguishable employer connected to those benefits and employer brand related predictors that are most important among the prospect and current employees (Bellou, Chaniotakis, Kehagias \& Rigopoulou, 2015).

Hence, it can be seen that the employer branding does provide various benefits to the organization and to the employees. It was emphasized that building merely an employer brand is not sufficient but it should be polished and improved in order to gain the maximum advantage of it and reach it to the society.

\section{Significance of Employer Branding in Asian Context}

As the demand for skilled, specialist, value adding employees is likely to increase dramatically because of the rapid technological advancement in the Asian region, the building of a proper employer brand is essential. The statistics found by the Maccarthy (2016) depicts that how the skill shortage has affected the countries due to the globalization and the technological advancement.

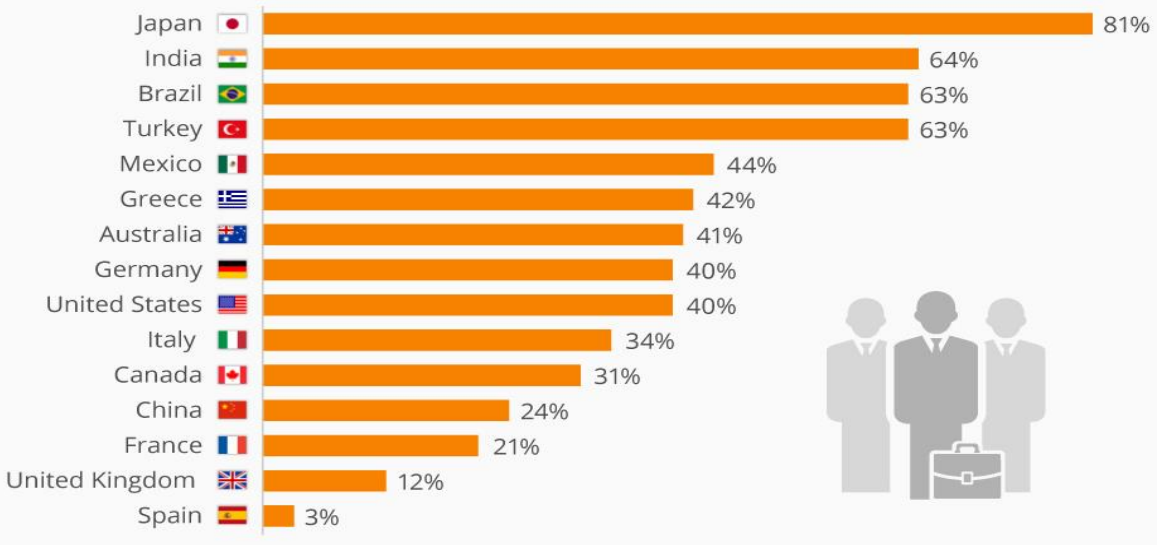

Figure 03: Countries Facing the Greatest Skills Shortage Source: Manpower Talent Shortage Survey via OECD

As depicted in figure 03, Japan, India and China are the most powerful countries in the Asian region who are suffering from the shortage of skilled labor. In order to get through this problem they have been focusing on some strategies to overcome this situation. Building a strong employer brand is one of those strategies. Further, it is reported in the Economist Magazine (2007) as Asians prefer to work for a well-known organization. So, in Asia, having a prestigious employer brand might help to attract the skilled labor.

\section{Employer Branding:}

Sri Lankan Evidence

Employer branding has been practiced properly by Sri Lankan companies but the amount and figures are not documented nor published much in the research context. However, Robertson 
(2013) has mentioned that the concern is given only for the product brand rankings rather than employer branding in Sri Lanka.

In Sri Lanka various surveys were conducted to assess the companies with greater relevance to employer branding. The Lanka Monthly Digest (LMD) conducted the Top 100 Most Respected Entities in Sri Lanka which does indirectly selecting the organization based on the power of the employer brand to the industry. The Neilson Company (2016) conducted a survey of 800 business people attached within the greater Colombo region. They were rated based on the ten criteria's namely: (i) financial performance; (ii) quality consciousness; (iii) management profile; (iv) work environment; (v) corporate social responsibility; (vi) honesty; (vii) innovation; (viii) dynamism; (ix) vision and (x) nation mindness. Most of these criteria are related to the image of the employer brand. But, how much these are adopted to the employer branding is questionable as there's no measures to quantify how these are adopted to the employer brand (Robertson, 2013).

\section{Theoretical Overview}

Social Identity Theory (SIT) well supports the current review which describes the human choices and human behavior as 'the extent to which people identify with a particular social group'. It will determine their inclination towards the group membership. Further, the Xie, Bagozzi \& Meland, (2015) cited evidence from Tajfel, (1978) and defined social identity as that part of an individual's self-concept which derives from his knowledge of his membership of a social group together with the value and emotional significance attached to that membership. In simple terms, social identity theory does emphasize on the recognition that individual gains emotionally and socially when they obtain membership in a certain organization.

Social identity does constitute three parts namely cognitive, evaluative, and emotional components. The cognitive component is the cognitive awareness of one's membership in social group, which is the self-categorization. The evaluative component can be defined as the positive and negative value implication attached to the group membership. Simply it can be termed as group self-esteem. The sense of emotional involvement with the group or the affective commitment is the emotional component of the social identity theory (Ellemers et al. (1999) as cited in Xie, Bagozzi \& Meland, (2015)).

Backhaus \& Tikoo (2004) mentioned that the social identity theory provides an additional support for the link between the employer brand and the recruitment. It does emphasize that the humans tend to derive their identity through the membership in certain social groups.

When referring to the above theoretical explanations the researcher can identify the social identity theory as a theory that provides the basis for which the individuals categorizing into different groups and how their self-esteem is built based on the impact that they gain by being a member of a particular organization.

Job market signaling also provides the foundation for this current study of employer branding. The job market it does signal about the various aspects of the organization through the employer 
brand and it does helps potentials to take decisions regarding their job.

Sending appropriate signals via the employer brand is one of the means that prospective employers can reduce potential employee information costs associated with the job information search as they do not need to invest in other sources (Wilden, Gudergan, Lings, 2010).

\section{Determinants of Employer Brand}

\section{Employee Reputation of the Company}

Employer reputation can be defined as the job seekers beliefs about public's affective evaluation of the organization. The Empirical research claimed that the employee reputation does associate with the corporate reputation and the employer familiarity.

Reputation also can be defined as the perceptual judgement of an organizations' past actions developed over a period of time (Jain \& Bhatt, 2014). Simply the reputation is how well the society knows about the organization based on the past actions.

Further, it can be stated that reputation is the symbolic aspect of the employer brand as it does indicate the aspects of the organization based on the past actions. Higher the company reputation higher the employer brand which is popular among the job markets.

As the employer brand does communicate the reputation or the image of the company to the corporate world it could be considered that the reputation does benefit the organization to attract the talent to an organization through the employer brand.

\section{Person Organization Fit (POF)}

The individual identity or the personal identity is defined as the concept that an individual develops about themselves that evolves around the course of life. The organizational identity is defined by the Albert and Whetten (1985) as the central, distinctive, and enduring characteristic of an organization. The organizational identity is another basis for the employee identification with the organization. It raises the question of "Who am I in relation to the organization?" (Witting, 2006). In simple terms, the individual identity is the uniqueness made for an individual whilst the organizational identity is how a firm is distinct compared to other firms in the industry.

The person organization fit shows the compatibility between the individual identity and organization identity and it does have a positive impact effect on the job choice decisions. Through the Employer Branding the characteristics within the organization should be effectively depicted in the process of attracting the potential candidates to the organization as the job applicants will try to evaluate whether the organizational identity will match their identity through the information that is accessible to them. As the Employer Branding is an effort of socialization, it should build up the organizational identity to match up the most capable talent identity within the job market.

Further, the providing of a realistic job preview will be benefited as it provides both the positive and negative aspects of the job and it will attract more potentials as make the expectations more accurate and help them to analyze their fit to the organization. 
Also, it has been found that through the job interviews and site visits have significant impact on subsequent employment decision as it does help the applicant to get an idea about the organization environment and evaluate whether it does match with their personality (Alshathry, Clarke \& Goodman, 2016). Hence, it is concluded that the employer brand depicts the various aspects of the organization indicating the person organization fit to the potential job seekers.

\section{The Job Attributes}

The organizational attributes are a key factor in applicant attraction and an applicant's positive first impression. Those attributes must be communicated to the potentials through the Employer Brand through integrating them to the same (Chabra \& Sharma, 2012).

The potential employee can observe the attributes of the job when they are searching for a job. Further, via the employer brand these benefits are manipulated to position the firm among the potential candidates. Those characteristics are workplace culture, salary, location etc. Further the effectiveness of the HR practices also reflects through the organization making it appeal and to add value to the organization (Neetu \& Prachi, 2014). Hence, it is concluded that those attributes will make the employer brand more powerful as they are being communicated through the brand.

Major components of a brand based on the job attributes are compensation benefits, work life balance, company culture and product brand strength. Amidst of all Neetu and Prachi (2014) identified that the stability of the company, work life balance and job security has been identified as the main attributes.

Similarly, Chabra \& Sharma (2012) reported that the common organizational attributes are compensation, career prospect and growth, job profile, brand name, culture, empowerment, training and development, innovative work practices, job security, recognition and appreciation and etc. They further emphasized the fact that the job portals should be updated in order to potentials to learn and get an idea of the same. These things should be signaled by the Employer Brand to the candidates.

\section{Employer Branding and Employee Recruitment}

As explained in the social identity theory, if a company does have a positive aspects of employee image (brand), the possibility of candidates being attracted to the company is higher. Further, Xie, Bagozzi \& Meland (2015) cited that the studies in the personnel psychology suggests that company reputation plays important role in the recruitment process. Hence, it can be mentioned that the more the company looks prestigious the more potentials will get attracted to the firm as being a member of the company will heighten its self-image.

The job signaling theory indicates that the image does signals the potentials regarding the psychological benefit that they can gain by being a member of the well-respected organization (Alshathry, Clarke \& Goodman, 2016). And based on the Signaling theory, the Employer Brand will signal the firm's values, systems, policies and depict the identity of the firm in order to the potential to match the organization for their 
requirements and further if these signals are properly communicated then the information costs associated with the search of the potential candidates will also reduce. (Wilden, Gudergan \& Lings, 2010). Simply it can be stated that more the organization attributes do match the personality of the individual the more the potentials will get attracted to the organization hence the pool of candidates will rise assisting the recruitment process.

The congruence on individual identity and organizational identity plays a part in the employer branding. This is mirrored out through the findings of Neetu and Prachi, (2014) they stated that person organization fit is one of the primary mechanisms that contribute in employee attraction.

The person organization fit indicates that potential applicants compare the employer brand image based on their needs and asses the match between their personalities. The better the match the employee will be attracted to the organization (Backhaus \& Tikoo, 2004). Further Neetu \& Prachi, (2014) stated that more the job attributes are attractive for a potential more they will get attracted to the company.

When considering the above evidences that were cited by the previous researchers the current researcher will be able to construct a relationship between the recruitment and employer branding. By making the social identity theory and the job signaling theory as the underlying theories the current researcher could conclude that more the company reputation and the job attributes are appealing to the potentials and higher the person organizational fit to the potentials the attraction to the organization would also heightens, which results the pool of candidates for a particular job within an organization to rise by assisting the recruitment process. As the reputation, person organization fit and the job attributes are communicated via the employer brand to the potentials in the job market it can be concluded that there is a stronger relationship between employee recruitment and employer branding.

\section{Conclusion}

Having reviewed the reported empirical findings up to date, and theoretical explanations, building on social identity theory and job signaling theory, it could be concluded that employer branding does significantly impact on employee recruitment. Further, it is found that the congruence between organizational identity and individual identity (personorganization-fit) plays a critical role in building the employer brand which in turn has a significant effect on employee recruitment. However, across the literature the type and the level of employer brand, and the gravity of the branding process is not clearly depicted and consistent. So that, it remains yet to be studied further in future research in the same domain with more empirical support. 


\section{References}

Alshathry, S., Clarke, M., \& Goodman, S. (2016). The role of employer brand equity in employee attraction and retention:a unified framework. International Journal of Organizational Analysis, 413-431.

Arachchige, B. J., \& Robertson, A. (2013). Employer attractiveness: comparative perceptions of undergraduate and postgraduate students. Sri Lanka Journal of Human Resource Management.

Backhaus, K., \& Tikoo, S. (2004). Conceptualizing and researching on employer branding. Career Developement International, 501-517.

Bellou, V., Chaniotakis, I., Kehagias, I., \& Rigopoulou, I. (2015). Employer brand of choice: An employee perspective. Journal of Business Economics and Management.

Capturing Talent : The Economist. (2017, October 21). Retrieved from Economist: http://www.economist.com.

Chabra, N. L., \& Sharma, S. (2012). Employer Branding: strategy for improving employer attractiveness. International Journal of Organizational Analysis, 48-60.

Desseler, G. (2014). Fundamentals of Human Resource Management. England: Pearson Education Limited.

Employer Branding In Sri Lanka. (2016). Retrieved from Daily FT: www.ft.lk.

Jain, N., \& Bhatt, P. (2014). Employment preferences of job applicants: unfolding employer brand determinants. Journal of management development, 634-652.

MacCurthy. (2017, October 21). The Chart : The countries facing the greatest skill shortage. Retrieved from statistica: https://www.statista.com

Robertson, A. (2013). Building the employer image : the HR Challenge. Proceedings of a the HR Dialogue - 2013. Department of Human Resource Management \& HRM Family, University of Sri Jayewardanepura .

Sivertzen, M. A., Nilsen, R. E., \& Olafsen, A. H. (2011). Employer branding: employer attractiveness and the use of social media. Journal of Product and Brand Management, 473-483.

Sokro, E. (2012). Impact of employer branding on employee attraction and retention. Europian Journal of Business and Management.

Theurer, C. P., Tumasjan, A., Welpe, I. M., \& Lievens, F. (2016). Employer Branding: A brand equity based literature review and research agenda. International Journal of Management Reviews, 1-25. 
Wilden, R., Gudergan, S., \& Lings, I. (2010). Employer Branding: strategic implications for staff recruitment. Journal of Marketing Management, 56-73.

Xie, C., Bagozzi, R. P., \& Meland, K. V. (2015). The impact of reputation and identity congruence on employer brand attractiveness. Marketing Intelligence and Planning, 124-146. 